\title{
EMPRESAS Y EMPRESARIOS EN EL REINO UNIDO. \\ LA VISIÓN DE MARSHALL Y DE KEYNES *
}

ANTONIO TORRERO MAÑAS

Universidad de Alcala

\begin{abstract}
RESUMEN
El objetivo del articulo es indagar sobre el conocimiento y sensibilidad de Keynes respecto al mundo empresarial. Como contrapunto de la visión de Keynes, se sitúa el planteamiento de Marshall. La conclusión fundamental del articulo es que Keynes, pese a su experiencia practica en el mundo de los negocios, tenia unas ideas sobre las empresas y los empresarios que dificultaban la percepción de las razones y consecuencias del declive industrial del Reino Unido. El análisis de Marshall, siendo éste un académico en sentido estricto, le parece al autor mejor orientado para la comprensión de la decadencia industrial inglesa.
\end{abstract}

\section{ABSTRACT}

The goal of this article is to inquire into the knowledge and sensibility of Keynes with regard to the entrepreneurial world. The vision of Keynes is faced to the interpretation of Marshall. The main conclusion is that Keyne's entrepreneurial ideas led him to misunderstand the reasons and consequences of the industrial decline of the U.K. On the contrary, Marshall, an strict academic, was capable of a better understanding of the English industrial decay.

\section{INTRODUCCIÓN}

La aspiración de Marshall era que le leyeran y comprendieran los hombres de negocios. La pretensión de Keynes era influir sobre la opinión pública, y su

* Este artículo constituye un apartado del libro en preparación La visión del fenómeno financiero en la obra de John Maynara Keynes.

Rezista de Hesiorsa Lcomima

Aro XIV Promatera-Verano 1996. N"2 
vision de los problemas diferia sustancialmente de la de su maestro y colegas de Cambridge. Keynes aportó una aproximación financiera, centrada en el análisis de los fenómenos económicos a través del funcionamiento de los mercados organizados, pero, en cambio, no se sintió atraído por determinados aspectos que habían ocupado la atención de sus compañeros de Universidad.

Limitando nuestra atención al contenido de este trabajo, dos temas sobresalen por el contraste de atención y dedicación que presta Keynes y los economistas de su entorno: el primero es la incidencia de las finanzas sobre la estructura industrial, cuestión muy significativa que no recibió atención de Keynes pero si de Marshall, Foxwell, Lavington y Clapham, entre otros; el segundo es la preocupación por el mundo de la empresa, en particular de la industrial y de los empresarios, temas éstos que aunque tienen eco en Keynes creemos están muy lejos de constituir un foco de inspiración fundamental, y desde luego se contemplan por Keynes con una perspectiva diferente a la de otros contemporáneos suyos.

A riesgo de un esquematismo demasiado acentuado, nos atreveriamos a decir que lo que en Marshall es consideración y respeto por la labor y figura del empresario, entendiendo como tal al hombre de negocios industrial y comercial, en Keynes es distanciamiento y decepción. El mundo de la empresa no era su mundo, pero tampoco era el ambiente de Marshall y, en cambio, éste tenía un profundo interés por el tema. Sin duda las preocupaciones de indole moral, el ambiente profesional y las relaciones personales son aspectos significativos que explican estas diferencias y, en lo que a Keynes concierne, es fundamental la incidencia de sus actividades profesionales en la orientación y selección de los temas objeto de su análisis económico. Para situar la visión de Keynes respecto al tema que nos ocupa, creemos que puede ser de interés hacer una referencia a las ideas de Marshall sobre las empresas y los empresarios, que nos sirva de punto de apoyo y también de contraste, para perfilar las ideas de Keynes sobre estas cuestiones.

\section{EMPRESAS Y EMPRESARIOS EN LA OBRA DE A. MARSHALL}

En sus Principles of Economics de 1890, Marshall, después de señalar que los móviles de actuación en economía no tienen por qué ser necesariamente egoístas, legitima el deseo de enriquecimiento: «el deseo de ganar dinero en si mismo no tiene por qué proceder de motivos de orden inferior, incluso cuando se destine a gastos personales. El dinero es un medio que permite un fin, y si los fines son nobles, el deseo de los medios no es innoble» ${ }^{1}$. Además del he-

\footnotetext{
Marshall (1964), p. 18
} 
cho de ganar dinero, la propia actividad de los negocios que, a primera vista, es posible que parezca falta de atractivos, puede constituir una fuente de satisfacción, ya que ofrece un campo en el que los hombres pueden ejercer sus fa. cultades y satisfacer sus instintos de emulación y poder: «Al igual que un caballo de carreras o un atleta tensa cada nervio para conseguir adelantar a sus competidores, y encuentra gran placer en ello, el fabricante o comerciante se siente a menudo mucho más estimulado por la esperanza de vencer a sus rivales que por el deseo de aumentar su fortuna» 2 .

Apunta Marshall un tema que después recogeria Keynes, cual es la pérdida de tensión que se produce en los procesos de sucesión en el mundo de los ne. gocios, pese a que los descendientes tengan las mayores ventajas para poder continuar con éxito la empresa; prefieren, a menudo, unos ingresos que les lleguen sin esfuerzo, a obtener otros muchos más elevados pero que su obtención implique tensión y ansiedad ${ }^{3}$. Conformidad que contrasta con la vitalidad y absoluta dedicación que observa en el mundo empresarial americano. Marshall advierte, sin embargo, de los efectos negativos que se producen cuando la competencia se lleva demasiado lejos, y los empresarios olvidan obligaciones que la mejora en todos los órdenes de la producción y distribución permiten hoy desarrollar, $y$ «subordinan el bienestar de sus empleados a su propio deseo de beneficion ${ }^{4}$. Estan lejos los tiempos en que la necesidad de supervivencia obligaba a expedientes de mayor dureza. «La nación ha crecido en riqueza, en salud, en educación y en moralidad; y ya no estamos obligados a subordinar casi cualquier otra consideración a la necesidad de incrementar el producto total de la industria»"

Esta llamada de atención a los excesos del industrialismo tiene mucho sentido en Marshall no sólo por corresponder a sus deseos más nobles y altruistas de promover el bienestar general, y de forma particular el de las clases menos favorecidas, sino porque le permite, como el lider indiscutido de los economis. tas, salir al paso de las acusaciones de moralistas como Carlyle y Ruskin que apuntaban a los economistas como culpables de la situación desastrosa de deterioro humano y ambiental al que habia conducido la competencia sin freno. Marshall levanta la bandera del humanitarismo de los economistas que «sin excepción abrazan la doctrina de que el bienestar del conjunto de la población debe ser el objetivo final de todos los esfuerzos privados y de la politica

2 Marshall (1964), p. 19.

3 Marshall (1964), p. 250.

- Marshall (1964), p. 621.

'Marshall (1964), p.651. 
pública» '. La sensibilidad de Marshall hacia esta cuestión es indicativa de sus inquietudes personales y de la misión que asigna a la ciencia económica y quiere salir al paso de la acusación que los moralistas hacen a los economistas de que éstos se habian mostrado contrarios -en especial Senior - a la reglamentación más humanitaria de la Factory Act ${ }^{\top}$. Este asunto es indicativo de la mezcla de preocupaciones morales y cientificas de Marshall y merece que le dediquemos una breve referencia.

El reproche más importante que hace Marshall a los seguidores de Ricardo es que no hayan percibido la capacidad de cambio tanto de las personas como en los hábitos e instituciones de la industria: «En particular, no percibieron que la pobreza es la causa principal de la debilidad y la ineficiencia, que a su vez son las razones de su pobreza: no tenian la fe que tenemos los economistas modernos en la posibilidad de que se produzcan mejoras muy importantes en las condiciones de las clases trabajadoras» ${ }^{8}$. En Industry and Trade (1919) vuelve a considerar esta cuestión y señala que los economistas siempre han apoyado la Factory $A c t{ }^{9}$, aclarando que la única excepción fue la de Senior en su juventud, pero que cuando profundizó en sus conocimientos de economía, rectificó y fue uno de sus más apasionados defensores. La argumentación de Senior estaba fundamentada en el supuesto de una productividad constante cualquiera que fuera la extensión de la jornada laboral, y alegó que el margen de rentabilidad era extremadamente sensible a dicha extensión, puesto que el producto del principio de la jornada se dedicaba a cubrir costes ${ }^{10}$.

En los trabajos de Marshall incluidos en los Memorials, editados por Pigou (1925), se encuentran las claves de su pensamiento social en lo que se refiere a la filosofía que debe inspirar la actuación de los empresarios ${ }^{11}$. Uno de los aspectos que Marshall destaca es la diferencia entre paises viejos, institucionalmente asentados, con una mejor distribución de la renta, y los nuevos, con territorios por explotar como Estados Unidos, donde los hombres de negocios continúan trabajando duramente y arriesgándose por el placer de hacerlo, ya que ello les gratifica, con independencia de la riqueza que hayan amasado. En

n Marshall (1964), p. 39.

Marshall (1964), p. 636.

8 Marshall (1964), pp. 630,631.

- Sobre la posición de los economistas clásicos respecto a las medidas legislativas que intentaban poner coto a la sobreexplotacion y situación lamentable del trabajo en las fábricas es fun. damental el trabajo de Blaug (1959).

in O'Brien (1975), pp. 384, 385.

11 En los Memorials se incluyen escritos de Marshall realizados entre 1872 y 1923 . Las referencias bibliográficas que hacemos de los Memorials llevarán el año de publicacion del trabajo seguido de la página del libro. 
Inglaterra, en cambio, pocos de los que se han enriquecido tienen una participación activa en las empresas, prefiriendo una colocación segura de su patrimonio:

los motivos que inducen a los hombres de negocios a competir por la riqueza no son en conjunto tan sórdidos como el mundo en general, y me veo forzado a admitir, los economistas en particular han asumido habitualmente... los hombres de negocios, tienen una naturaleza muy parecida a los cientificos; tienen el mismo «instinto de la caza» y muchos de ellos tienen identica capacidad de verse estimulados a realizar grandes y febriles esfuerzos por emulaciones que no son sórdidas e innobles ${ }^{12}$.

Los cientificos no se preocupan del dinero ya que éste no es la medida de su éxito, pero en el mundo de los negocios el dinero es el indicador que mide el triunfo: "Por eso los mejores hombres de negocios desean ganar dinero, pero muchos de ellos no se preocupan por él en sí mismo; lo desean principalmente como la prueba más convincente para ellos mismos y para otros de que han tenido éxito" ${ }^{13}$. Marshall fue un decidido defensor del movimiento cooperativo y con ocasión del Congreso anual de esta organización se dirige a los asistentes en los términos siguientes:

El placer que se deriva de un incremento de riqueza es principalmente el placer de la adquisición, de la victoria sobre los rivales, de la conciencia de la prueba de la propia fuerza, de ser admirado y envidiado por aquellos que uno ha dejado atrás, y de ser admirado y tolerado por aquellos con los que conjuntamente se ha elevadon; [y añade en otra parte] «han pasado los dias de la caballe. rosidad romántica. Los caballeros andantes ya no rescatan indefensas doncellas de los castillos de terribles gigantes o dragones carniceros que vomitan volcanes de llamas; pero hay una llamada tan poderosa como siempre para el coraje y el autosacrificio caballeroso por ideales grandes que merecen la pena ${ }^{14}$.

El trabajo de Marshall en el que se refleja con mayor nitidez su idealismo data de 1907 15: «La caballerosidad en los negocios incluye el espíritu del bien público, así como en la guerra incluía la desinteresada lealtad a la causa del principe, del país o de la cruzada. Pero comprenden también la propia satisfacción de realizar cosas dificiles y nobles sólo porque son nobles y difíciles..., ${ }^{16}$.

12 Memorials (1890), p. 266

13 Memorials (1890), pp. 281, 282.

14 Memorials (1899), pp. 238, 251.

15 Nos referimos a Social Possibilities of Economic Chivalry. Existe version española. Alfred Marshall. Obras escogidas. Fondo de Cultura Económica. México 1949.

it Memorials (1907), p. 330. 
Es importante distinguir el dinero que se gana de forma noble y caballerosa del que no responde a estas caracteristicas y esta tarea de valoración:

Es el primer deber de todos los economistas que estan en relacion con los hombres de negocios y aprenden de éstos. Debe hacerse un esfuerzo para convencer a la opinión pública que ha de actuar como un tribunal de honor extraoficial en estas materias. Entonces la posesión de riquezas, aunque ésta sea grande, no constituira una patente para el éxito social si se ha logrado con trampas. por informaciones falsas, por tratos fraudulentos o por medio de la destrucción desleal de los competidores; $y$ aquellas otras empresas que sean nobles por sus propositos y por los métodos que emplean, incluso aunque no consigan grandes provechos, recibiran la gratitud y la admiración públicas merecidas, igual que el trabajo del hombre de ciencia, del literato o del artista la reciben ahora.» «El hombre rico con sentimientos caballerosos puede ayudar a los municipios en la realización de proyectos ambiciosos y caros. Como, por ejemplo, el de la señorita Octavia Hill para ir abriendo gradualmente varias amplias zonas de espacios libres y adecuadamente cultivados a distancias diferentes dentro y alrededor de las grandes ciudades, y unir con otras por avenidas transversales por las que los trabajadores y sus familias puedan pasear mientras los hijos juegan en los campos de recreo ${ }^{17}$.

Los párrafos que hemos entresacado de sus obras más caracteristicas, a los efectos del tema que tratamos, creemos que son suficientes para dar una idea de los presupuestos morales que subyacen en la obra marshaliana y sin la que es dificil comprender el sentido completo de alguna de sus proposiciones analiticas, como brillantemente ha expuesto Whitaker ${ }^{18}$. Como Keynes destaco, Marshall, como sus colegas Sidgwick y Ward en Cambridge, pertenece a la tribu de sabios y pastores, $y$ además fue un cientifico; en esa doble naturaleza radica la mezcla de fuerza y debilidad de su obra ${ }^{19}$.

$\mathrm{Si}$ de los escritos incluidos en los Memorials encontramos los presupuestos morales de Marshall, en Industry and Trade (1919) se recoge su visión del proceso productivo y de la situación de la actividad cconómica de su época. A juicio de Keynes: «El libro es una mina más que un ferrocarril, como los Principios, una cantera en la que buscar tesoros escondidos» ${ }^{20}$. La diferencia entre ambas cosas ha sido muy adecuadamente sintetizada por Gonce. Para este au. tor, Industry and Trade debe ser considerado como un libro de organización in-

1) Memorials (1907), pp. 343,345.

ik Whitaker (1977), p. 453.

${ }^{19} \mathrm{CW}$ (1924), X, p. 173. Todas las referencias a escritos de Keynes proceden de los Collected Writings ( $C W$ ). Las citas especifican el año de publicación, el volumen de los $\mathrm{CW}$ en números romanos en que se incluyen y, por último, la página correspondiente.

21" $\mathrm{CW}$ (1924). X. p. 228. 
dustrial: «Industry and Trade va más allá de los Principles examinando el cambio tecnológico como un proceso a muy largo plazo y situando el análisis en una secuencia de actividades que incluye investigación básica, investigación aplicada, innovación e investigación en desarrollo» ${ }^{21}$.

En la presentación del libro, Marshall expone su inquietud por acercarse a la realidad del mundo del trabajo y de la industria:

Ha pasado casi medio siglo desde que me propuse obtener por mi mismo algun conocimiento de los problemas industriales, consiguiendo permiso para visitar uno o más trabajos representativos en cada rama industrial importante. Intenté conseguir un cierto conocimiento de la técnica mecánica (la técnica quimica estaba fuera de mi alcancel que me capacitara para comprender los recursos y el modo de operar de las fäbricas elementales de uso general: Pretendia tambien estudiar las relaciones entre la técnica y las condiciones de empleo de hombres y mujeres 22 .

Esa posición de acercarse a los problemas de la producción con una actitud humilde de aprendizaje esta presente en Industry and Trade, que es un libro de arrastre muy desigual en cuanto al contenido y al mérito con el que se abordan las diferentes cuestiones. Atendiendo a nuestros objetivos, nos interesa hacer referencia ahora a dos aspectos: a la incidencia de la estructura educativa sobre el mundo de la empresa y a la admiración de Marshall hacia el sistema de producción y organización de los Estados Unidos.

Marshall es plenamente consciente del atraso tecnológico del Reino Unido $y$ de la relación que existe entre éste y el sistema educativo. En una nota a pie de página, alude a un informe sobre la atención del sistema educativo hacia las materias técnicas que se hizo en Inglaterra después de que una Comisión viajara a Alemania y Suiza: «Todas las Universidades y Colegios en Inglaterra tienen menos estudiantes "investigando en las ramas de quimica avanzada" que una sola Universidad alemana (se refiere a la de Munich) que fue visitada» ${ }^{23}$. La preparación de los hombres de negocios, de los directivos de las empresas es un tema que le preocupa hondamente. En etapas de reestructuración económica, de gran dinamismo, de cambios importantes en definitiva, los hombres que protagonizan los tiempos turbulentos son personas de genio e intuición, con facultades innatas que tienen poco que ver con la educación recibida. Esas circunstancias se daban hace una generación en América y en el último cuarto del siglo dieciocho $y$ en el primero del xix en el Reino Unido.

\footnotetext{
${ }^{21}(1982)$, p. 337

22 (1919), p. VII.

$23(1919)$, p. 97.
} 
Sin embargo, el periodo de consolidación exige ya una dependencia creciente de afacultades $y$ aptitudes que necesitan ser desarrolladas por el estudio paciente, si no por alguna clave de disciplina académica» ${ }^{24}$. En esa línea, América, que sigue los pasos de Alemania en la habilidad para aplicar a la ciencia aplicaciones técnicas, es pionera, sin embargo, en la aplicación de una preparación universitaria amplia para la dirección de los negocios ${ }^{25}$. En un apéndice, escrito en 1903, del libro que seguimos, Industry and Trade, Marshall deja ya constancia del atraso relativo del Reino Unido en cuanto a la educación específica de los hombres de negocios respecto a América y Alemania y destaca el hecho de que no se está actuando enérgicamente para acortar la distancia entonces existente ${ }^{26}$.

Es interesante resaltar que Marshall percibe que la gran ventaja del Reino Unido fue el dinamismo comercial ejercido en solitario, apoyado en un sistema financiero avanzado, cuestión apuntada por Bagehot; dinamismo que el Reino Unido habia perdido, pero que Marshall no considera consecuencia de un proceso inevitable ligado con el concepto de pais viejo. Otros países viejos pueden experimentar súbitamente una sacudida y su gente despertar ante la atracción de los métodos técnicos modernos, aplicando con fuerza esta energia latente. Japón es el ejemplo de un pais viejo que se ha renovado en la actual generación ${ }^{27}$.

Hemos aludido ya a la admiración de Marshall por América. Marshall viajó a los Estados Unidos en 1875 y durante cuatro meses tuvo numerosos contactos tanto académicos como con personas importantes. Keynes señala al respecto que el principal propósito de Marshall era el «estudio de los problemas de la Protección de un Nuevo Pais" y que el contacto con América le causó una gran impresión influyendo en sus obras posteriores.

Acostumbraba a decir que no fue tanto lo que aprendió realmente como lo que se dio cuenta que necesitaba aprender, que aprendió a ver las cosas en su debida proporción y que tenía datos suficientes para esperar la futura supremacia de los Estados Unidos, para conocer sus causas y las direcciones que tomaria ${ }^{28}$.

Efectivamente, Marshall muestra su admiración por el hombre de negocios americano, surgido de la selección natural, que no tiene inclinaciones por los

\footnotetext{
24 (1919), p. 360 .

25 (1919), p. 361.

26 (1919), p. 821.

27 (1919), pp. 92, 141, 142.

28 C.W (1924), X, p. 176.
} 
fastos, sino que trabaja duramente: «Esta dedicación exclusiva hacia un solo propósito supone alguna pérdida en la vida del individuo; pero la constructiva fuerza económica que da a América, en esta fase de desarrollo, es únican 29. Esta visión del papel fundamental que desempeñan los hombres emprendedores explica la admiración que le producen los grandes líderes empresariales americanos ${ }^{30}$; el dinamismo del nuevo mundo le induce a mirar, con alguna preocupación, pero sin criticar duramente los excesos de la concentración de poder que se produce en esa época tan turbulenta de los Estados Unidos, y a considerarlos fruto de una situación y de una historia peculiar ${ }^{31}$. La lejanía y la referencia del escaso dinamismo de la sociedad y de la economia en franco declive como la del Reino Unido, frente a la fortaleza vital de los Estados Unidos, explican, en nuestra opinión, que la sensibilidad social de Marshall no ahonde en los aspectos negativos de la experiencia americana y, por tanto, que su visión sea tan distinta a la de un analista tan duro y lúcido como Veblen.

El aspecto que consideramos más significativo respecto a Industry and Tra$d e$, le es muy cercano a Keynes: la percepción por parte de Marshall de la «naturaleza precaria e inconsistente de los cimientos sobre los que se habia erigido la preponderancia industrial de Inglaterram ${ }^{32}$. La consideración de que una determinada situación puede ser consecuencia de factores no recurrentes, y que es fundamental analizar la actualidad de los supuestos que sirven de soporte a la creencia de que se trata de una posición estable, es un punto básico en la aproximación analítica de Keynes; sin embargo, creemos que éste no la emplea con la agudeza que en él es habitual para percibir con nitidez la auténtica realidad del declive industrial inglés, y analizar las razones por las que éste se produce. De ser acertada nuestra interpretación, seguramente nos puede ayudar a comprender esta carencia la idea que tenia Keynes, su visión, en definitiva, del funcionamiento de las empresas y del papel de los empresarios, cuestión que abordamos a continuación.

\section{EMPRESAS Y EMPRESARIOS EN LA VISIÓN DE KEYNES}

Uno de los aspectos más significativos para comprender el alcance y las limitaciones del pensamiento de Keynes es su visión del mundo de la empresa,

29 (1919), p. 156.

3" Las referencias en Industry and Trade a este respecto son numerosas. Ver, por ejemplo: Rockefeller (p. 359n), Vanderbilt (p. 534n), J. P. Morgan (p. 541n).

"(1919), p. 345 .

32 CW (1924), X, p. 228. 
su concepto acerca de los empresarios, de los móviles que les animan y de sus reacciones. La cuestión tiene importancia para cualquier economista que se plantee como objeto de análisis la comprensión de una realidad nacional inserta en el mundo, lo que no tiene por qué comportar necesariamente una aproximación exclusivamente macroeconómica, pero entendemos que es especial. mente relevante en el caso de Keynes, al que se le concede como caracteristicas distintivas de su personalidad, en relación con el mundo exclusivamente académico, un conocimiento directo del mundo de los negocios. Sin embargo, a nuestro juicio, una limitación esencial de la visión económica de Keynes es su escasa sensibilidad para percibir la trascendencia del hecho empresarial. Nuestra posicion es que Keynes estaba cerca no del mundo de las empresas, sino de una determinada clase de empresas; que estaba familiarizado y era sensible no al fenómeno de la inversión, sino a una determinada parcela de la misma; creemos, además, que el conocimiento detallado de algunas ramas concretas del mundo empresarial, y de ciertas parcelas del fenómeno inversor, lejos de facilitarle la comprensión de las empresas y de la inversión, y aun de la auténtica situación de la economía inglesa, particulamente del sector industrial, actuaba más bien como obstáculo cerrándole el paso a otras vertientes muy importantes de estos fenomenos, pero hacia las que no sentia demasiado interés. Como último punto de esta breve introducción, debemos destacar que la personalidad de Keynes, junto a su fama de conocedor del mundo de los negocios, daban a sus análisis una generalidad y aceptación que consideramos excesiva, oscureciendo la percepción de la parcialidad de su análisis.

Esas son las ideas de fondo, el cañamazo sobre el que intentaremos describir la visión de Keynes del mundo de la empresa y de los empresarios; hemos de resaltar, como caracteristica adicional, la autoridad que conferia a Keynes, en las polémicas y cambios de impresiones, la capacidad de llevar al interlocutor al campo que éste no dominaba y del que se suponia que Keynes era un experto ${ }^{33}$, de manera que si para los empresarios era un economista académico de prestigio, para sus colegas universitarios tenía la aureola del conocimiento directo del mundo de los negocios.

El conocimiento directo de Keynes de las empresas y sectores industriales era ciertamente limitado y se reduce al análisis de la situación del carbón y, sobre todo, a su actividad como abanderado de la reestructuración de la industria textil de Lancashire. En sus escritos sobre problemas especificamente industriales destaca su participación en el Informe del Partido Liberal: Britain's

"Fn Torrero (1993, p. 235-236) se enfatizan esas caracteristicas de Keynes como economista, explicables por la variedad de sus experiencias vitales y por su personalidad. 
Industrial Future. Es importante señalar que los escritos y actividades de Keynes en torno a estas cuestiones se concentraron en 1926 y 1927, esto es, cuan. do empezaban a dejarse sentir en la estructura industrial del Reino Unido las consecuencias de la revalorización de la libra que acompañó al retorno al patrón oro en 1925, y su preocupación surge del análisis de las consecuencias de esta decision.

De los biógrafos de Keynes, seguramente ha sido Skidelsky el que más atención ha prestado a la limitación de Keynes para la comprensión de la realidad de su tiempo. Skidelsky precisa que el mundo de Keynes fue el de las universidades antiguas, el de la politica, el de la administración pública y el de las finanzas, con el añadido cultural de Bloomsbury; sus amigos extranjeros eran economistas, banqueros, intelectuales, periodistas, pero pocos manufactureros podian contarse entre ellos; el conocimiento del mundo de los negocios era teórico y estadistico ${ }^{34}$, con la excepción, añadimos nosotros, del mundo de la inversión financiera. Como tendremos oportunidad de comprobar, Keynes sentia escaso respeto por el mundo de los negocios y, en este sentido, no compartia las ideas de Marshall que hemos esbozado anteriormente, las cuales calificaba de románticas e ingenuas.

Ya en sus primeros trabajos apunta su opinion sobre los empresarios. En un articulo de 1922 escrito para los Reconstruction Supplements del Manchester Guardian, Keynes șe refiere al empresario como «una criatura instintiva y elemental, primitiva en su forma de expresión y falta de sofisticación en el conocimiento de si mismo" ${ }^{35}$. Esta definición la elimina del artículo en su adaptación para $A$ Tract on Monetary Reform y también para la versión de Essays in Persuasion ${ }^{36}$.

En The End of Laissez-Faire ${ }^{37}$ Keynes rechaza explicitamente la concepción del empresario que tenia Marshall, y lo hace apostillando con ironia dos parrafos del texto más representativo de éste en torno a esta cuestión en los que su maestro elogia la imaginación, el arrojo, la versatilidad y la capacidad de coordinación de los hombres de empresa ${ }^{38}$. Frente al idealismo del elogio de Marshall, Keynes replica:

it (1992), pp. 258, 259.

" CW (1922), IV, p. 24.

3o El articulo es "The Consequences to Society of Changes in the Value of Money", publicado el 27 de julio de 1922, que, con el mismo titulo, constituye el primer capítulo del Tract on Monetary Reform (1923). En Essays in Persuasion (1931) aparece una versión reducida del capitulo del Tract con el titulo Social Consequences of Changes in the Value of Money.

CW (1926), IX.pp. 286, 287.

" Los dos parrafos que le sirven de referencia a Keynes para concretar su discrepancia co. rresponden a Social Possibilities of Econame Chivalry (Memorials 1907, p. 332 ). 
Este es un hermoso cuadro del gran capitulo de industria, del gran patrón-individual, que nos sirve al tiempo que se sirve a si mismo, tal y como lo hace cualquier otro artista. Sin embargo, a su vez, se esta convirtiendo en un idolo deslucido. Cada vez dudamos más de que sea el quien nos conduzca al paraíso de la mano... Sugerir una acción social en favor del bien público a la City de Londres es como discutir el Origen de las Especies con un obispo de hace sesenta años ${ }^{39}$.

Es de notar que cuando Marshall elogia al hombre de empresa, no estaba tomando como referencia los del sector financiero, que son, sin embargo, a los que recurre Keynes para discrepar del candor de su maestro.

El mundo empresarial que contempla Keynes, aparte de que su epicentro sea el del sector financiero, es el mundo de la gran empresa, de la sociedad por acciones en la que aparece desligada la gerencia y la propiedad y en la que se ha llegado a un grado tal de consolidación que los beneficios pasan a un segundo plano; en estas macroempresas, sólidas, bien establecidas, perfectamente engrasadas, ya no puede decirse, según Keynes, que se muevan por móviles estrictamente privados, sino que se hacen copartícipes del servicio público. Keynes advierte, en repetidas ocasiones, que ya no existen empresarios capaces de planear grandes proyectos, pero no se plantea las razones de esa escasez, sino que se limita a apelar al plantel de empleados públicos que considera capaces de suplir esta carencia.

\section{LA IMPORTANCIA DEL BENEFICIO EMPRESARIAL}

Dentro de esta concepción, el papel del beneficio como móvil de las iniciativas empresariales ocupa un lugar ambiguo en los escritos económicos de Keynes por más que en ocasiones ponga énfasis en su importancia; sin embargo, al hacerlo, está aludiendo normalmente más a que el nivel de beneficios sea suficiente para remunerar el capital invertido que a la legitimidad de maximizarlo. Su primer biógrafo, Harrod, advierte que Keynes no era demasiado partidario del lucro como móvil de la vida económica, aunque tampoco lo fuera de que el Estado dirigiera las industrias ${ }^{40}$. En un libro excelente, Wiener ${ }^{41}$ llama la atención sobre el hecho de que lo más atractivo para Keynes de la experiencia comunista de los años veinte no radicaba en su pretensión de mayor

\footnotetext{
39 CW (1926), IX, p. 287

40 (1951), p. 384.

4 (1981), p. 91 .
} 
eficiencia económica en la que no creía, sino en la critica socialista al amor al dinero que Keynes consideraba el problema moral de su época ${ }^{42}$.

En efecto, en los articulos que escribe con ocasión de su viaje a Rusia en $1925^{+3}$, Keynes destaca como la esencia de la doctrina comunista el despego del individuo y de la comunidad hacia el amor por el dinero, y esto le fascina ya que constituye un intento de articular la sociedad reduciendo la importancia relativa de la motivación económica y, por tanto, sin que la obtención del beneficio constituya el barometro de aprobación y responsabilidad social ${ }^{44}$. Por eso lamenta la situación del Reino Unido en una de sus reflexiones más significativas al respecto.

En Inglaterra hoy, un joven honesto y de talento, al iniciarse en la vida activa, sopesará las ventajas de ingresar en la Administración o de buscar fortuna en los negocios; y la opinión pública no le apreciará menos si prefiere la segunda opción. Hacer dinero, como tal, en una escala tan grande como sea posible, no es socialmente menos respetable y tal vez lo es más que una vida dedicada al servicio del estado, o de la religión, la educación, el estudio o el arte "s?

En su trabajo The End of Laissez-Faire, Keynes destaca el paralelismo entre el darwinismo y el laissez-faire; de la misma forma que Darwin explica la selección natural por medio de la competencia sexual, el individualista invoca el amor al dinero actuando mediante el propósito de conseguir beneficios, como elemento coadyuvante en la selección natural para obtener el mayor nivel de producción to. Además de criticar la causación económica conducente a que se cumplan los efectos beneficiosos que se apoyan en supuestos irreales, hemos de destacar, desde la perspectiva que ahora nos ocupa, que el objetivo de Keynes no es eliminar el beneficio como móvil de actuación, sino moderar su trascendencia dando más peso a las acciones colectivas de manera que la incidencia del amor al dinero fuera lo más reducida posible; esta compatibilización de la acción individual dirigida por afán de lucro, con la acción colectiva presidida por ideales más generosos y altruistas es lo que late en el «capitalismo sabiamente manejado» al que Keynes aspiraba ${ }^{47}$.

12 CW (1925), IX, p. 268.

43 Se trata de tres articulos aparecidos en octubre de 1925 en The Nation and Atbenaeum con cl titulo «A short View of Russia» (IX, pp. 253-271).

"4 CW (1925), IX, pp. 259, 260.

"s CW (1925), IX, p. 260.

th CW (1926), IX, p. 284.

" CW (1926), IX, pp. 292-294. 
En estas coordenadas, teniendo en cuenta el optimismo histórico de Keynes en cuanto a la evolución de la sociedad y su confianza en las posibilidades de los economistas para dirigirla, hay que situar manifestaciones en apariencia tan contradictorias como las que encontramos en la conferencia de tono profético impartida en Madrid en 1930, y en las llamadas de atención del Treatise on Money y en sus declaraciones ante el Macmillan Committee acerca de la necesidad de restablecer el nivel de beneficios de las empresas. En efecto, la conferencia de Madrid ${ }^{48}$ es un canto a la esperanza, al desprendimiento, al regreso a las virtudes tradicionales. «La avaricia es un vicio, la práctica de la usura es una mala conducta, y el amor al dinero es detestable" ${ }^{49}$, y al optimismo del futuro: el problema económico será resuelto, o estará en vías de solución en un espacio inferior al siglo y, por tanto, no constituye el «problema permanente de la raza humanas ${ }^{50}$.

La dura e inmediata realidad lleva a Keynes, en la práctica, sin embargo, a situar como pivote de la recuperación económica la recomposición del benefi. cio empresarial: «En tanto que los beneficios sean la fuerza directiva de la empresa, no pueden situarse por debajo del nivel al que haga posible la inversion" " ${ }^{1}$. Se trata no de altas tasas de beneficios, sino de las que permitan la reducción del desempleo: «El desempleo existe porque los empresarios han sido privados del beneficio», ya que «vivimos en una sociedad organizada de tal modo que la actividad productiva depende de que el hombre de negocios tenga la esperanza de un beneficio razonable» 52 .

La visión de Keynes del beneficio empresarial es que alcance un nivel suficiente no que constituya el elemento que tensione a la sociedad y que la consecución del mismo agilice e incentive la adopción de decisiones, sino que sea bastante para no interferir con un proceso ordenado, suave, sin rupturas ni es-

4* El título de la conferencia impartida en Madrid en junio de 1930, «Economic Possibilities for Our Grandchildren», se publicaría en octubre del mismo año en The Nation and Athenaeum. (1930, IX, pp. 321.332).

49 CW (1930), IX, p. 331.

51" Sobre la conferencia de Madrid, vista desde España, son fundamentales los trabajos de Fuentes Quintana (1983) y Velarde (1988). Son asimismo interesantes las paginas que le dedica Beltran (1988, pp. 95-99). No podemos detenernos en esta cuestión, pero si debemos resaltar la anotación de Fuentes Quintana (1983, p. 317): "Hay tambien en las declaraciones de Keynes en Madrid un consejo poco keynesiano: el acento puesto en sus entrevistas sobre la investigación y el desarrollo tecnológico como apoyos de una politica de progreso económicom. En efecto, como destacamos en repetidas ocasiones en nuestro libro en preparación sobre Keynes, esta cuestion no constituye un punto fuerte de las preocupaciones del economista ingles.

5 CW $(1930), X X$, p. 107

$\$ 2$ C.W (1931), IX, p1). 232, 234. 
tridencias. Se trata pues de una concepción muy conservadora; como Skidelsky ha señalado, aunque Keynes era un jugador por temperamento y afición, no aceptaba riesgos sociales ${ }^{53}$. Ese proceso ordenado precisa, en la concepción de Keynes, que los beneficios sean suficientes pero que no sean excesivos ni inmerecidos. De ahi que en The Economic Consequences of the Peace arremetiera con dureza contra los beneficios inmoderados propiciados por el desorden inflacionista, ya que no solamente se trata de beneficios inmerecidos que provocan el resentimiento de los que sufren las consecuencias, sino que llevan a la pérdida del autorrespeto y erosionan la confianza en la aportación social de los empresarios:

El terror y la timidez personal de esta clase de individuos es ahora tan grande, ha disminuido tanto su confianza en el puesto que ocupa y la necesidad que tiene de ellos el cuerpo social, que son victimas fáciles de la intimidación. Esto no era asi en Inglaterra hace veinticinco años. Entonces los capitalistas creían en ellos mismos, en su valor para la sociedad, en lo apropiado del disfrute perdurable de sus riquezas y en el ejercicio ilimitado de su poder ${ }^{54}$.

Años más tarde, de una forma más radical expondria la clave de la legitimación empresarial que radica en el beneficio obtenido con esfuerzo:

Convertir al hombre de negocios en un logrero (profiteer) es dinamitar el capitalismo, porque destruye el equilibrio psicológico que permite el mantenimiento de recompensas desiguales. La doctrina económica de los beneficios normales, vagamente aceptada por cada uno, es una condición necesaria para la justificación del capitalismo. El hombre de negocios, es sólo tolerable en tanto que pueda sostenerse que sus ganancias tienen alguna relación con lo que, en algún sentido de manera amplia, sus actividades hayan contribuido a la sociedad 5 .

Keynes seria fiel durante toda su vida a estas ideas de moderación y legitimidad en la percepción y disfrute de las rentas, en favor de la estabilidad social. A comienzos de 1937 señala: «La evolución natural debe ser permitir un

" (1992), p. 267.

it CW (1919), II, p. 150. Smithies (1972, p. 426) revisando The Economic Consequences of the Peace hace notar como la relevancia del capitulo en el que la cita anterior se inserta, aunque no se haga explicito, es que en esa atmósfera de desconcierto social y pérdida de autoestima empre. sarial que implica la inflación, no puede esperarse sino que unicamente gobiernos débiles pue dan hacer frente a las indemnizaciones de la guerra mediante la emisión de moneda o repudiación y renegociación de la deuda.

" CWW (1922), IV, p. 24; IX, p. 69 
nivel de consumo decente para cada uno; y, cuando esto sea suficientemente alto, encaminar la ocupación de nuestras energias en los intereses no económicos de nuestras vidas» ${ }^{56}$.

Esta forma de considerar empresas y empresarios es conveniente encuadrarla en el clima en el que se desarrolla la vida de Keynes. Seguramente el crítico más acerado, y en nuestra opinión certero, de las limitaciones implícitas en el enfoque de Keynes ha sido H. G. Johnson, que nos ha dejado un testimonio magnifico de los valores sociales predominantes en el circulo de Cambridge y de las formas de vida que daban lugar a unas relaciones paternalistas con los empleados de los Colegios a cambio de seguridad en el empleo y pro. tección frente a los accidentes inesperados de la vida; la contrapartida era la conformidad con las condiciones salariales, y la lealtad y agradecimiento por el conjunto de beneficios adicionales (subsidios a la vivienda, facilidades para practicar deportes, etc.). Tomando ese universo como modelo, que es lo que a su juicio hizo Keynes, es fácil concebir a los hombres de negocios como una clase inferior a la de los profesores, y entender que éstos consideren el mundo de los negocios, o de la política, como propios de inteligencias de segundo nivel comparadas con el intelecto puro de los miembros de la Facultad, cuyo análisis de los asuntos públicos se realizaba pensando en el exclusivo interés general ${ }^{5}$.

La critica de H. G. Johnson nos parece brillante y en su conjunto acertada, pero deja como principal cabo suelto el hecho de que Keynes no era un representante ortodoxo del pensamiento colegial de Cambridge, sino que por el contrario era una personalidad deslumbrante capaz de conciliar dos mundos: el lejano de los negocios financieros y el inmediato de la economía de la Universidad y la discusión de los grandes asuntos públicos. Además, como hemos apuntado, Marshall tenía una sensibilidad y una admiracion, si se quiere ingenua, por el mundo de los negocios que no percibimos en Keynes, como tampoco encontramos rastro en la obra de éste por las preocupaciones que alentaban los análisis de Lavington o del propio Foxwell, que le era tan cercano. De manera que, en conclusión, la visión de Keynes no respondía en exclusiva al espiritu y la tradición de Cambridge, sino que en esa atmósfera de desprendimiento y lejania, y en la tradición del análisis económico de Cambridge, Keynes incrusta su peripecia personal, que no incorporaba la cercanía del hecho

\footnotetext{
so CW (1937), XXI, p. 393

s Johnson (1977), p. 393.
} 
empresarial, sino la familiaridad de un financiero que tenia en la City su propio campo de trabajo y el de sus relaciones profesionales más cercanas.

\section{EL EMPRESARIO COMO AGENTE ECONÓMICO}

El tipo de interés es una variable muy importante en el análisis de Keynes de las decisiones de inversión de los empresarios; una elevación de tipos dificulta la adopción de decisiones, pero es clave la actitud de los inversores su estado de ánimo, lo que denominaria «animal spirits» en la Teoria General, y éstos dependen de que existan personas decididas a arriesgarse en un futuro siempre desconocido. Keynes se decanta por una mayor participación de los poderes públicos en el proceso inversor no porque no existan proyectos, sino ante la inexistencia de personas emprendedoras dispuestas a animar la vida económica o asumir el riesgo inherente a la misma aceptando una módica remuneración por su función y como recompensa del capital invertido. «Estas personas "con previsión de futuro" sobre proyectos nuevos, costosos y moderamente remunerados no existen. Si no existiera el "Manchester Ship Canal" ¿eso significaria que un sindicato de inversores privados se lanzaría a construirlo hoy? ${ }^{5}$.

No faltan, pues, proyectos de inversión; el Reino Unido no es una obra acabada, lo que escasea es el impulso empresarial, y Keynes lo atribuye al efecto degenerativo de la herencia:

Creo que las raices del declive intelectual del capitalismo individualista deben encontrarse en una institución que no es caracteristica del mismo, sino que lo tomó del sistema social del feudalismo que le precedió; me refiero al principio hereditario. El principio hereditario en la transmision de la riqueza y el control de los negocios es la razón por la que el liderazgo capitalista es débil y estúpido. Está demasiado dominado por los hombres de la tercera generación. Nada producirà la decadencia de una institución social con más certeza que su ligazón con el principio hereditario. Un ejemplo de esto es la Iglesia, la más antigua de nuestras instituciones, que siempre se ha mantenido al margen del vicio hereditario ${ }^{59}$.

El párrafo anterior es reproducido por Skdelsky ${ }^{\circ}$, , que insiste en la creencia de Keynes en el ciclo de las tres generaciones: el hombre de energía c ima-

\footnotetext{
s\& CW (1924), XIX, p. 230.

s9 CW (1925). IX, p. 299.

(*) (1992). p. 259.
} 
ginación que crea el negocio, el hijo que lo mantiene y el nieto que lo quiebra, o como señalaria Keynes en una emisión radiofónica:

Sin duda, mi propia opinion es que la influencia hereditaria en la designa. ción de los altos cargos de las empresas es uno de los grandes peligros para la eficiencia de los negocios britanicos. Muchas de nuestras industrias están alcanzando una edad dificil. Estan llegando a ser negocios de segunda y tercera generación. Están pasando a manos de hombres que no los han creado y que posiblemente no hubieran podido crearlos ${ }^{\text {th }}$.

Keynes, sin embargo, no profundiza en las razones de esa decadencia, ya que ese ciclo vital se producía en todos los países, como en los Estados Unidos, por ejemplo, pero, en cambio, se daban unas condiciones en América que permitian la regeneración constante de la clase empresarial, la revitalización continua de los visionarios del futuro. Eso es lo que faltaba en el Reino Unido, y no porque se tratara de un pais viejo (Japón también lo era), sino porque la sociedad inglesa no valoraba el hecho empresarial, lo cual hundia sus raices en los valores imperantes en la sociedad inglesa, que no apreciaba socialmente la actividad empresarial, asi como las pautas y categorias de comportamiento que tal actividad implica. Keynes, en nuestra opinión, era, en este sentido, un buen ejemplo del sentir de las clases altas del Reino Unido.

Cuando comienzan a producirse en Inglaterra las tensiones sociales correctamente anticipadas por Keynes, como consecuencia del retorno al patrón oro de la libra en 1925, y se anuncia la huelga general, Keynes hace referencia a los empresarios en el guión de una conferencia como «estrechos e ignorantes, incapaces de adaptarse» ${ }^{62}$. Su toma de contacto con los problemas del Lancashire, le lleve a denostar la gestión de los agentes económicos, dirigiendo sus dardos de forma muy especial a los empresarios:

La mala gestion del valor de la moneda y del crédito por el Banco de Inglaterra desde la guerra, la torpeza obstinada de los propietarios de las minas de carbón, la conducta aparentemente suicida de los lideres de Lancashire, plantea la cuestion de la preparación y adaptación de nuestros hombres de negocios en esta edad moderna que mezcla progreso y regresión. ¿Que ha sucedido a esta clase de la que estábamos orgullosos hace una o dos generaciones? ¿Son demasiado obstinados? ¿O qué? ¿Es que demasiados no se han levantado por ellos mismos sino que se han elevado sobre los hombros de sus padres y abuelos? En cuanto a los propietarios de las minas de carbón, todas esas alusiones pueden 
ser ciertas. ¿Pero qué sucede con los muchachos de Lancashire, que eran el orgullo de Inglaterra por su sagacidad? ¿Qué tienen ellos que decir? h3.

Si la estimación de Keynes por la clase empresarial era escasa en el periodo de reestructuración industrial y de reducido crecimiento económico que sigue al retorno del Reino Unido al patrón oro, los años de la depresión no hacen sino aumentar su despego hacia lo que considera actitud pasiva y falta de energia para combatir el desajuste en la organización que habia provocado el derrumbe. En carta publica a $G$. B. Shaw, Keynes le reprocha su simpatia por el régimen soviético, indicándole que la critica marxista corresponde a un capitalismo del pasado, y que en la segunda mitad del siglo xIX aún era plausible decir que los capitalistas, «esto es los lideres de la City y los capitanes de la industria», tenian el poder $y$, por consiguiente, la organización de la sociedad respondia a esta circunstancia. Sin embargo, a partir de 1870 se opera una evolución que ha modificado ese tipo de sociedad:

Una de las principales causas puede haber sido una suerte de ley natural que prescribe que los gigantes del bosque no tengan sucesores inmediatos... Cuando los gigantes cayeron con los años, descubrimos que una clase diferente de arboles habia surgido... El capitalista ha perdido la fuente de su fuerza interior, su seguridad y confianza en si mismo, su voluntad indomable, su creencia en su propia grandeza y en su valor incuestionable para la sociedad ${ }^{\text {b4 }}$.

En el año 1934, también en carta pública dirigida al presidente de los Estados Unidos F. D. Roosevelt, Keynes le expone que la dificultad fundamental de la recuperación económica reside en el desconcierto de los hombres de negocios que se sienten conducidos hacia terrenos desconocidos: «El hombre de negocios, que puede ser adaptable, sagaz y rápido cuando actúa en su propio terreno, es a menudo conservador y convencional en los aspectos más amplios de la política económica y social» ${ }^{65}$. Los hombres de negocios son muy influenciables $y$ lo que hace falta - según Keynes- es que alguien con la personalidad suficiente los persuada de que los malos tiempos quedan atrás, para que miren el futuro con optimismo y cambie, en consecuencia, el signo de sus decisiones empresariales. Tres años más tarde, en otra misiva a Roosevelt, esta vez de carácter privado, expresa con mayor libertad su opinión sobre los empresarios:

\footnotetext{
"CW (1926), XIX, p. 585

in CW $(1934)$ XXVIII, p. 33.

os CW (1934), XXI, p. 324
} 
Los hombres de negocios tienen un conjunto de ilusiones diferentes a las $\mathrm{de}$ los políticos; y necesitan, en consecuencia, un manejo distinto. Son, sin embargo, mucho más dóciles que los politicos y, al mismo tiempo, les seduce y asusta el brillo de la publicidad, son fácilmente persuasibles para que sean «patriotas»; estan vacilantes, aturdidos, sin cluda asustados $y$, sin embargo, demasiado predispuestos a una perspectiva optimista, quizá vanidosos pero muy inseguros de si mismos, pateticamente sensibles a una palabra amable. Puede $\mathrm{Vd}$. hacer lo que quiera con ellos, si los trata (incluso a los más importantes), no como a lobos y tigres, sino como a animales domésticos por naturaleza, incluso aunque no se hayan criado y educado como hubiera sido deseable. Es un error pensar que pueden ser más inmorales que los políticos ob

El párrafo anterior es una buena muestra del carácter y de la personalidad de Keynes. No puede sorprender que uno de sus criticos, H. G. Johnson, señale que su teoria empresarial era la de un académico inglés habituado a ver cómo los alumnos de segundo nivel intelectual encuentran acomodo en la in. dustria britanica donde su exito dependerá de los animal spirits o de la perseverancia inglesa pero que, en cualquier caso, merecen sólo una modesta recompensa en remuneración y prestigio social ${ }^{67}$.

A partir de estas ideas es sencillo deslizarse y considerar que el empresario es un gestor gregario fácilmente influenciable $y$, naturalmente, si no cumple ya con su misión histórica de anticipar el futuro y de aceptar posiciones de ries. go, es una clase perfectamente prescindible sobre todo en tiempos de desconcierto económico, cuando queda en evidencia su falta de protagonismo. En su comparecencia ante el Macmillan Committee señala con claridad: "La cuantia de la inversión... en el país depende de la acción de los hombres de negocios, de que piensen que vale la pena seguir adelante con una empresa o nom 68 . Sin embargo, en el Treatise on Money reduce el alcance del protagonismo individual y apunta que la prospección es dificil, requiere más información que la disponible y, en consecuencia, los empresarios se guian por la experiencia corriente suplementada por generalizaciones amplias ${ }^{69}$. Si tenemos en cuenta la reticencia de Keynes a aceptar la existencia de derechos a perpetuidad cuando éstos se sitúan en contra de los intereses generales, y el menguante papel que asigna a los empresarios, no es sorprendente el paso siguiente: rechazar que la mejor alternativa sea que los hombres de negocios decidan respecto a las inversiones y en vez de eso se conciba que una elite encargada por el gobierno

\footnotetext{
th CW (1938), XXI. p. 438

6.) $(1976)$, p. 373

ox C.W (1930), XX, p. 73.

6\% CW (1930), V, p. 144
} 
asuma esa función, pasando por encima del hecho de que las empresas sean privadas ${ }^{i 0}$.

En consonancia con sus ideas al respecto, Keynes no ve la necesidad, como Marshall, de que las universidades se preocupen de la especialización tendiendo a facilitar la preparación e integración en el mundo de los negocios. Los conocimientos especificos no tienen demasiada importancia, son fácilmente aprendidos en el propio ejercicio del trabajo - su propio caso es un buen ejemplo - y la Universidad debe procurar una formación de tipo general:

Sería un error para las universidades intentar una formación vocacional. Su misión es desarrollar la inteligencia y el carácter de los hombres de forma que

- pueda captar de manera relativamente rapida los detalles especificos del negocio en el que desarrolle su trabajo $7 !$.

\section{EMPRESAS PÚBLICAS Y PRIVADAS}

En una conferencia de 1927, con motivo de las reuniones de la Escuela de Verano del Partido Liberal, en Cambridge ${ }^{72}$, Keynes se plantea la importancia y alcance de las empresas públicas y privadas; entiende que las empresas públicas son necesarias e inevitables, que tienen ya cierta importancia, pero aún queda un campo muy grande para la empresa privada, que «sólo un lunático pretenderia nacionalizar». La linea de demarcación entre empresas públicas y privadas no debe establecerse por principios objetivos, sino en función de las necesidades que se vayan planteando. Keynes realiza un inventario de las grandes empresas existentes y establece como linea de demarcación entre empresas públicas y privadas la obtención de beneficios como objetivo fundamental, incluyendo entre las públicas las nacionalizadas total o parcialmente así como otras empresas estrechamente reguladas por el Estado en las que no se persigue sólo la obtención de beneficios. El inventario de este conjunto de empresas públicas o semipúblicas permite concluir que el capital de éstas supone los dos tercios del capital total de las grandes empresas del pais ${ }^{3}$.

in Gordon (1992), p. 154.

: CW (1927), XIX, p. 654.

i2 El contenido de la conferencia «The Public and The Private Concern" no se ha conserva. do. El editor de los CW ha incluido el reportaje de la misma publicado por The Manchester Guardian (august 1927), que recoge con amplitud el contenido de la misma y de donde tomamos las referencias (XIX, pp. 695.698). La conferencia, por otra parte, recoge los puntos de vista de Key. nes sobre la organización empresarial que integran el Libro 2 del informe elaborado bajo el pa trocinio del Partido Liberal: Brittan's Industrial Future (1928).

¿C.W' (1927), XIX, p. 695. 
Keynes considera un tema menor plantear la extensión deseable de las empresas públicas, y pone énfasis en la mejora de la organización y de la gestión para que la prestación de los servicios públicos se realice de la forma más adecuada, y una cuestión fundamental al respecto es que los directivos se escojan por su capacidad de gestión:

No veo... por qué no podemos crear en este pais un gran servicio público que se ocupe de gestionar la parte empresarial de las empresas publicas, reclutado del conjunto de la población con la misma habilidad y la misma gran tradi. ción de nuestro Servicio Civil administrativo. Podria realizarse una gran captación de personas para ocupar plazas en las grandes empresas públicas, y establecer un sistema que permitiera la promoción rápida de los excepcional. mente eficientes, con unos salarios satisfactorios para los que alcanzaran los puestos de dirección ${ }^{\text {i4 }}$.

En las propias empresas privadas se observa la tendencia a requerir una mayor intervención del Estado con objeto de corregir los principales defectos e ineficiencias. El punto clave de la evolución de estas empresas ha sido el paso hacia la sociedad por acciones con un gran número de propietarios y directivos asalariados, posición que sitúa a estas empresas a medio camino entre la típica empresa privada y la pública. En estas grandes empresas privadas es preciso garantizar el derecho a la información para que los accionistas puedan conocer su situación real, y de ahí el énfasis de Keynes en una reforma drástica de la información contable que deba hacerse pública, y de un papel más relevante para los auditores que refrende la documentación contable de carácter público, de manera que los inversores puedan conocer la auténtica situación de las empresas. La mejora de la información pública de las empresas privadas no sólo es imprescindible para el público inversor, sino que permite conocer y combatir las posiciones monopolisticas que puedan engendrarse en determinados sectores, pero este peligro, nos parece observar, no constituye una preocupación especial para Keynes, que está más alarmado por la competencia destructiva de un conjunto de pequeños productores que por los excesos que puedan derivarse de la posición preeminente de una gran empresa:

Puede ser verdad que un gran complejo empresarial como Imperial Quemical Industries, en determinadas condiciones llegue a ser un monopolio peligroso. Deben existir los mecanismos adecuados para vigilar una situación de este tipo y asegurar la publicidad adecuada. Pero en cuanto se refiere a eficiencia en la producción y control, que después de todo es el ingrediente esencial del éxito

is CW (1927), XIX, p. 697. 
nacional en la industria, me parece absolutamente innegable que una empresa como la de Sir Alfred Mond (Presidente de Imperial Quemical Industries) ha alcanzado un nivel mucho mas alto que aquellas industrias integradas por un gran numero de entidades pequeñas e independientes ocupadas principalmente en una competencia destructiva ${ }^{75}$.

Esta es, en sintesis, la visión que tiene Keynes de las empresas. El economista inglés considera solamente el mundo de la gran empresa, entiende que éstas incorporan aspectos públicos cada vez más pronunciados y que, por tanto, se difumina la frontera entre las empresas públicas y las privadas. En este progresivo acercamiento a lo público, Keynes ofrece las soluciones del mundo que conoce, que es el mundo de la Administración Pública, en el que, a su juicio, un cuerpo de altos funcionarios desempeñan su mision con lealtad, desinterés y eficacia. La mayor parte de las empresas públicas y semipúblicas están dedicadas a la prestación de servicios domésticos y, por tanto, prácticamente a salvo de la competencia exterior, y esta distinción entre empresas expuestas y protegidas tiene especial importancia en el análisis de Keynes.

El punto débil de la economia británica, esto es, su dificultad para competir en un mundo con adversarios comerciales cada vez más poderosos, precisaba de un fermento empresarial que diera vitalidad al tejido industrial y comercial y permitiera su renovación, pero estas cuestiones quedan fuera del ámbito de su visión y de su interés intelectual. Su única cercanía al mundo de la em. presa industrial y exportadora fue la experiencia de Lancashire, de la que sacó una impresión claramente negativa acerca de las posibilidades de las pequeñas industrias en un entorno fuertemente competitivo. Apuntaremos, además, que su insistencia respecto a la publicidad y auditoria de los estados contables está conectada no sólo con las cuestiones de organización industrial o vigilancia de posiciones monopolistas, sino con sus actividades inversoras, que mostraban una marcada preferencia por la inversión en acciones; Keynes encontraba, en este campo, grandes defectos de información para poder formarse una idea cabal del contenido y posibilidades de las empresas cotizadas en el mercado bursatil.

Esta visión del mundo empresarial está presente en la Teoria General, de forma especial en el último capitulo ${ }^{76}$, cuya limitación es que considera una situación institucional del Reino Unido como permanente. Nos parece que sus opiniones respecto al mundo empresarial tienen una importancia significativa

is CW (1927), XIX, p. 728

76 El ticulo del capitulo 24 es bien expresivo: «Notas finales sobre la filosofia social a que podria conducir la Teoria General» (1936, VII, pp. 372-384). 
en su concepción global del problema económico y en el análisis de las alternativas que plantea. Como señaló Wright ${ }^{77}$, es verdad que la gran corporación moderna puede mantener negocios por un periodo de tiempo largo y basar su actuación en el empleo de fondos generados internamente sin verse acuciada por las expectativas de buenos beneficios para la continuación de su actividad, pero eso no permite concluir que los beneficios no son necesarios en una economia dinámica o que no es necesario preocuparse acerca de que la inversión tenga estimulos suficientes. Gruchy is ha advertido que Keynes concreta su atención en la demanda, no en la oferta, y que si hubiera estado más preocupado por los problemas tecnológicos habria podido explicar de forma más adecuada la evolución del desarrollo de la economia capitalista.

\section{COMPETITIVIDAD DE LA INDUSTRIA INGLESA}

Hemos señalado la escasa sensibilidad de Keynes hacia el proceso productivo, los aspectos tecnológicos y, en general, respecto de las condiciones que actúan desde el lado de la oferta. La principal consecuencia que se deriva de esta carencia es, en nuestra opinión, que Keynes no percibe la magnitud del declive profundo de la estructura industrial inglesa, la obsolescencia y esclerosis advertidas por Marshall en las últimas décadas del siglo XIX, situación que no se debe a elementos coyunturales sino a factores de carácter permanente ligados a los valores aceptados por la sociedad inglesa; de esta forma, la pérdida de competitividad se estaba haciendo crónica tanto por el anquilosamiento inglés como por el progreso de los paises europeos y, sobre todo, el de los Estados Unidos. Marshall da pruebas de ser perfectamente consciente del declive industrial y competitivo de su pais:

Se necesitan tres hombres de Glasgow para hacer el trabajo de un americano. Atribuyo esto en un cuarto a los empleadores, la mitad a los nuevos sindicalistas y el cuarto restante no lo imputo. Quiero decir que cuando un hombre trabaja perezosamente una jornada corta en términos relativos, consigue alguna ganancia que es la contrapartida a su pérdida de eficiencia ${ }^{79}$.

Esta conciencia de pérdida de competitividad no la encontramos en Keynes en la misma medida, aun cuando éste reaccione y culpe a los agentes eco-

\footnotetext{
$(1945)$, p. 35.

is (1949), p. 266.

is Memorials (1897), p. 401.
} 
númicos de la falta de vitalidad de la economía, pero subyace, pese a sus airados comentarios, un notable y, nos atrevemos a decir, sorprendente optimismo sobre la capacidad competitiva del Reino Unido si el sistema económico estu. viera bien dirigido. Keynes considera más la capacidad potencial física y laboral de producción, que la económicamente posible dadas las condiciones reales que impone una economia abierta al exterior. Las referencias que siguen pretenden mostrar esta faceta de Keynes que nos parece significativa para comprender las posibilidades y carencias de su análisis económico.

Keynes atribuye buena parte de los problemas ingleses de la década de los veinte a la politica recesiva para preparar la vuelta al patrón oro, y des. pués de 1925 a los que generaba el ajuste de la economia inglesa a una paridad sobrevalorada. Desde el comienzo de la década de los veinte, dirigiría su atención para explicar la atonia de la economia inglesa a las variables financieras. En una conferencia, que pronuncia en 1922, atribuye la falta de dinamismo al tipo de cambio que tomaba posiciones ya para preparar el terreno y cumplir el confesado objetivo de la vuelta al parrón oro con la pari. dad de la preguerra:

La tardanza en la recuperación del comercio en este país comparado con lo que sucede en América, es debida en medida importante al curso del tipo de cambio. El tremendo impulso que ha recibido el comercio en América a traves de la subida de los precios apenas se ha reflejado aqui. La elevación de los pre. cios en America la hemos compensado aqui con las mejoras del tipo de cambio de la esterlina, de manera que las cosas han quedado como estaban ${ }^{80}$.

Un pärafo del Treatise on Money recoge con nitidez el protagonismo que Keynes asigna a las decisiones financieras de carácter macroeconómico como responsables del escaso vigor de la economia británica:

Podiamos haber evitado la mayor parte de los problemas de los últimos diez años, y ser tan ricos, quizá como los Estados Unidos si hubiéramos estabilizado nuestra posicion monetaria al nivel de inflación de ingresos (income inflation) existente a finales de 1920 , esto es, un 175 por ciento del de antes de la guerra. Incidentalmente, esto hubiera dejado la carga real de la deuda emitida por la guerra en los dos tercios de su cifra actual. La politica adoptada aumentó la severidad del problema de la deuda en un 50 por ciento, y produjo una década de desempleo que puede haber reducido la producción de riqueza en más de 1.000 millones de libras 81 . 
Con este planteamiento, es comprensible el alborozo con el que recibe el abandono del patrón oro en 1931, puesto que posibilitaba una politica autónoma desligada de la servidumbre financiera del exterior. Keynes ve despejadas las condiciones de una industria como la del algodón en Lancashire que arrastraba una larga crisis: «En casi todas las líneas de la producción de algodón Lancashire es probablemente el productor mas barato del mundo. La principal preocupación de los fabricantes es por cuánto tiempo permanecerán Italia, Checoslovaquia y Japón en el patrón oro. Tienen confianza de que en tanto permanezcan en el patrón oro podran batir a esos peligrosos competidores en los mercados mundiales» ${ }^{82}$. El optimismo no se limita al textil, sino que incluye también el carbón, hierro y acero y no se advierte sólo en las industrias tradicionales; en las nuevas industrias su optimismo es también desbordante: «No me sorprendería, por ejemplo, ver grandes progresos en la exportación de automóviles. Me parece que no está más allá del limite de nuestras posibilidades que dentro de dos años este pais haya ocupado el lugar de los Estados Unidos como productor lider de automóviles en el mercado internacional» ${ }^{3}$. El optimismo de Keynes se refiere al Reino Unido, ya que considera entonces que la depresión continuara en tanto no se reacrive la construcción en Estados Unidos y se anime la inversión en el resto del mundo, de manera que existen limites claros a la mejora relativa del Reino Unido, y no pueden ignorarse las servidumbres que impone un marco internacional recesivo. Meses más tarde se reafirma en su optimismo industrial y competitivo:

Gran Bretaña, hoy de nuevo, el productor más barato del mundo. Creo que nuestra industria textil puede producir a menor coste que sus principales competidores en una gama amplia de calidades. Creo que podemos armar buques a menor coste que cualquiera. Creo que tenemos la oportunidad de captar la mayor parte de las exportaciones mundiales en automoviles y camiones. Todo esto lo veremos con el tiempo. Las fuerzas que se han puesto en pie el pasado septiembre (el abandono del patrón oro) no han tenido aún tiempo suficiente para que produzcan sus efectos por completo. Pero asi y todo, Gran Bretana decidi. damente es hoy el pais más prospero del mundo ${ }^{84}$.

Keynes no asigna la importancia que nosotros concedemos al auténtico problema del Reino Unido, que radicaba, como ya hemos expuesto, en la obsolescencia del sector industrial y, sobre todo, en la escasa disposición de la sociedad inglesa para que en su seno surgieran iniciativas empresariales que

\footnotetext{
k2 CW (1931), XXI, p. 6.

s* CW (1931), XXI, p. 7.

st CW (19321, XXI, pp. 56, 57
} 
regeneraran y modernizaran el tejido industrial inglés. Lo que Keynes observa es el despilfarro que suponen los recursos ociosos de la economía británica, en términos de capacidad productiva sin utilizar y desempleo, pero no se plantea, con la claridad precisa, las limitaciones que impone la competitividad con el exterior a la utilización económica de los recursos disponibles; no pone el énfasis, en definitiva, en las servidumbres de una economia abierta, y cuando lo hace es para poner obstaculos que hagan posible la producción inglesa con mayores costes, no para proponer las reformas internas que pudieran vivificar, a medio y largo plazo, por supuesto, el mundo empresarial inglés. En esas coordenadas hav que situar el siguiente análisis de Keynes analizando las mejoras en la producción y en la productividad que se habian producido en la industria inglesa hasta 1935, año para el que Keynes se queja en 1938, están disponibles los últimos datos:

Si concedemos que se han producido mejoras adicionales desde 1935 e imaginamos que la población industrial estuviera empleada al completo, es fácil ver la vasta capacidad potencial de producción que existe comparada con la existente en 1924. Esto ayuda a explicar lo que de otra forma nos dejaria perplejos sobre la economia alemana. Si la industria británica pudiera trabajar a pleno rendimiento con los sistemas modernos de eficiencia, la producción adicional que excederia a nuestras necesidades hace unos años sería suficiente para proporcionar un volumen prodigioso de recursos disponibles para proyectos de paz o defensa. Los recursos del país radican en su actual capacidad fisica de producción, y de ellos no existe escasez. Por el contratio, estamos permitiendo que se evapore sin materializarse un gran volumen de riqueza potencial ${ }^{85}$.

El desarrollo del conflicto bélico y los informes de Keynes para ordenar la situación en la segunda posguerra ponen de relieve el extraordinario optimismo de Keynes respecto a las posibilidades de la economia inglesa, contando con las mejoras de producción y productividad que permitiria la introducción de los avances técnicos experimentados en la guerra en las actividades comerciales $\mathrm{e}$ industriales de la paz:

Cuando el futuro aparece negro, me consuelo pensando que la industria británica dificilmente puede ser tan ineficiente como antes de la guerra. Tengo confianza en que podamos aumentar en un 50 por ciento la producción en la industria y en la agricultura simplemente poniendo en acción métodos y técnicas que ya existen ${ }^{86}$.

" C.W (1938), XXI, p. 481.

*n C.W (1943), XXVII, p. 259. 
El aumento de la eficiencia industrial de la posguerra se apoyará en el progreso de la electrificación, las mejoras de los motores de combustión interna, la familiaridad con la producción masiva de bienes adquirida por los fabrican. tes, la introducción de máquinas diseñadas por los americanos, y además de la mejora de las técnicas de producción, el adelanto en los métodos de organización y distribución permitirán un salto importante ${ }^{8 i}$. En los años de la segunda guerra mundial, Keynes tiene conciencia, no obstante, de la distancia que separa su pais de los Estados Unidos en términos de productividad. La comparación de la producción por persona segun el Censo de Producción del Reino Unido en 1935, con el Censo de Manufacturas de los Estados Unidos, muestra que la producción por persona en América es cuatro veces mayor, $\mathrm{e}$ incluso superior, en siderurgia, automóviles y radios, a cerca de tres veces en maquinaria, aunque sólo en un 20 ó 30 por ciento mayor en textiles de algodón. En el conjunto, la producción por persona es el doble de la británica, aunque las diferencias en la producción por hora trabajada es aún mayor, puesto que la jornada de trabajo en Estados Unidos es más reducida ${ }^{88}$.

Esta comparación arroja resultados que nos parecen demoledores para una economia tan expuesta al exterior como la del Reino Unido; afecta a los sectores maduros, y a los nuevos, como los automóviles, en los que Keynes tenia la esperanza de que el Reino Unido liderara el mercado mundial, y creemos que deberian haber inducido a una reflexión profunda que pusiera de relieve las carencias competitivas británicas. El análisis de Keynes en estos temas no está a la altura de su indiscutible genio en cuestiones macroeconómicas de caracter financiero, y su indagación de las razones explicativas resulta sorprendente:

Parte de esta superioridad puede ser debida a ventajas naturales de tamaño de mercado y a otras razones. Pero la mayor parte de la explicación debe imputarse al uso de maquinaria más moderna, metodos y equipos de producción, que son susceptibles de ser introducidos en este pais. ¿No debemos esperar, y sin duda decidir, superar en parte al menos esta inferioridad evitable? ${ }^{89}$.

El esfuerzo bélico inglés, la capacidad de organización del Reino Unido en unas circunstancias tan dramáticas, seguramente influyeron en la evaluación de las posibilidades de recuperación del atraso tecnológico. Keynes deja constancia de que en la fabricación de municiones el Reino Unido habia acortado las

\footnotetext{
R. CW (1942), XXVII, p. 282.

sx CW (1943), XXVII, pp. 337, 338.

ny CW (1943), XXVII, p. 338.
} 
distancias respecto a la mayor productividad americana hasta reducirla a una franja entre el 25.50 por ciento. El éxito en este campo se hace extensible a numerosas ramas industriales que experimentaron mejoras sustanciales en la dimensión y organización adoptándose los modernos métodos americanos de producción en masa:

Una vez que las ideas generales que subyacen en las prácticas más modernas han sido aprendidas, son facilmente aplicables a productos diferentes de aquéllos en los que se ha experimentado primero. Tambien la innata y la originalidad de los disenadores e inventores de este pais se ha confirmado por la experiencia de esta guerra. Con los métodos modernos de aplicación apoyandolos serán capaces de nuevo de liderar el mundo ${ }^{90}$

En la situación del Reino Unido, nos parece casi inevitable preguntarse sobre las causas por las que la organización productiva de los Estados Unidos fuera tan superior, $y$ los equipos y los métodos utilizados tan modernos; la observación de Keynes es que están disponibles y se trata simplemente de introducirlos en la sociedad británica, pero las fuerzas que han conducido a que se hayan generado en USA y no en el Reino Unido no despierta, en apariencia, su interes. Puede argumentarse que es fácil decir esto ahora que tenemos constancia del sostenido declive industrial inglés, y que en la época de Keynes era más comprensible considerar la distancia en productividad como algo fácilmente subsanable para un pais de la fuerza de Inglaterra, que luchaba en una segunda guerra mundial victoriosa, y después de superar con entereza la soledad de los primeros años de la contienda. $\mathrm{El}$ argumento tiene, sin duda, alguna validez, pero aceptada esta dificultad, no podemos dejar de pensar que, además, la optimista y voluntarista posición de Keynes tiene su origen en su escasa sensibilidad para percibir la trascendencia del magma social que hace posible la generación de impulsos empresariales, que hace posible, en definitiva, el surgimiento de los animal spirits, de personas capaces de arrostrar riesgos. Creemos, en sintesis, que Marshall, viviendo en una época en que el atraso in glés no era tan patente, tenia una mayor sensibilidad para percibir la trascendencia del retraso y para indagar en las razones que lo habían producido. A riesgo de mostrarnos reiterativos, consideramos estos aspectos fundamentales para la comprensión de la visión de la economia de Keynes.

El escenario previsto por Keynes para la economia de la posguerra era el de una Inglaterra que precisaba aumentar sus exportaciones, objetivo factible ya que sus competidores principales, Alemania y Japón, no podrian hacerlo du-

\footnotetext{
"1) C.W (1943), XXVII, p. 339.
} 
rante cierto tiempo, y los paises de la Commonwealth, antes de ser competidores fuertes, precisaban de cuantiosas importaciones de bienes de equipo que podria suministrarles el Reino Unido. En estas condiciones, el principal competidor era los Estados Unidos, respecto al que Inglaterra tenia la ventaja del coste más reducido de su mano de obra:

El salario por hora en este pais es ahora, en promedio, algo inferior a $2 s$, pero el coste en EEUU se situa alrededor de $5 \mathrm{~s}(\$ 1)$; seria innecesariamente derrotista para los industriales britanicos asumir como inevitable que sus propios métodos son tan ineficientes en rérminos relativos, que no puedan competir directamente en manufacturas con los americanos que pagan salarios dos veces y media más elevados ${ }^{91}$.

Un año más tarde, con la finalización del conflicto, Keynes plantea de nuevo la posibilidad de competir del Reino Unido, teniendo como baza esencial la diferencia salarial apuntada con Estados Unidos, y señala que, a pesar de la "celebrada ineficiencia» de los manufactureros ingleses, es dificil pensar que no aprovechen esta diferencia de costes. En cualquier caso, la opinión respecto a la capacidad empresarial del empresariado inglés, se pone de relieve en el comentario sarcástico que incluye en una Memorandum suyo que circuló en el gabinete de guerra: «Si por algún triste desliz geográfico, la Fuerza Aérea Americana (es demasiado tarde ya para esperar demasiado del enemigo) destruyera cada factoría de la costa del Noreste y en Lancashire (a una hora en la que los directores estuvieran sentados alli y no hubiera nadie más), no tendriamos nada que temer» ${ }^{92}$. En el mismo mes de su muerte, expresa su confianza en la competitividad de la industria británica, basándose ya de forma exclusiva en los bajos salarios en relación a los de Estados Unidos: «No puedo creer que seamos tan ineficientes como para no competir sobre la base de esta amplia disparidad salarial» ${ }^{43}$.

\section{CONCLUSIONES}

Como hemos señalado, Keynes no tiene la inclinación de Marshall por obtener conocimientos del mundo de la empresa, y ni por familia ni por tradición tenia conexión alguna con el comercio o la industria: tampoco su expe.

${ }^{41}$ CW (1944), XXIV, pp. 59, 60.

92 (.W (1945), XXIV, p. 262.

s) CW (1946), XXVII, p. 485 
riencia profesional le puso en relación con empresas manufactureras y sus contactos e intercambios personales de información, en el ámbito mercantil, se concentraban en torno a los mercados financieros. Lo anterior no quiere decir que a Keynes no le interesara ni le preocupara la situación de las empresas industriales. Un economista como él, con una orientación pragmática y vocación reformista, que vivió en una sociedad que habia sido pionera en el desarrollo industrial, en la que las tensiones más graves y los problemas sociales más agudos provenian de la situación de las empresas industriales forzosamente tenía que preocuparse de la situación de las empresas industriales. El conocimiento de Keynes y su interés por estas cuestiones tiene un enfoque determinado y la información que capta y el objeto de su análisis responde al mismo. A nuestro juicio, las empresas industriales entran en su área de atención a través de cuatro vías fundamentales: 1) por la evaluación de las empresas cotizadas en la bolsa con propósitos de calibrar las posibilidades de inversión; 2) al analizar las consecuencias sobre el sector industrial de las medidas de política de carácter general; 31 mediante el estudio de los problemas sectoriales concretos, cuyo caso esencial y, prácticamente único, es su intervención en la resolución de los problemas del sector textil en Lancashire, y 4) al considerar la ordenación del sector público empresarial, o de manera más amplia, del universo empresarial que tiene caracteristicas y comportamientos que no responden estrictamente al modelo de empresas privadas (public concern).

La primera vía de conocimiento respondería al enfoque del análisis financiero que contempla entre las posibilidades de inversión la de comprar acciones, y que se preocupa de conocer la situación de las empresas con objeto de formar una opinión respecto a si su contenido patrimonial y sus expectativas de beneficios están recogidas en la cotización y adoptar decisiones de inversión en función del juicio que obtenga al respecto, situado éste en el entorno del comportamiento del mercado bursátil. La segunda fuente de inspiración procede de los analisis de Keynes respecto a la incidencia en los distintos sectores y actividades de las medidas de carácter macroeconómico. Nos referimos, sobre todo, a los efectos sectoriales que producen las modificaciones de la paridad cambiaria y de los tipos de interés. Su análisis de los sectores protegidos y a resguardo de la competencia internacional iniciado en 1925 es de una gran brillantez y actualidad. El tercer canal de información es el estudio especifico de las empresas y sectores industriales, esto es, el análisis de situaciones concretas de orden microeconómico, y destaca en este sentido su intervención en la industria textil de Lancashire, experiencia de la que obtuvo enseñanzas negativas respecto de la capacidad de un sector con multitud de empresas, maduro, en crisis y expuesto a la competencia internacional, para 
reestructurarse mediante la actuación de las fuerzas del mercado, y la extrema dificultad para racionalizarlo mediante la concertación. El último venero que hemos apuntado es la ordenación del mundo empresarial público, semipúblico y asimilado, destacando la aportación de Keynes en la investigación del Partido Liberal, Britain's Industrial Future.

Estas cuestiones son importantes y los frutos del análisis inspirado en esas líneas de experiencia y conocimientos son relevantes y en muchos casos magistrales. En otros aspectos, sin embargo, la sensibilidad de Keynes para percibir y ordenar los problemas no era la misma. Su preocupación por el avance tecnológico, la educación especializada o la gestión empresarial es realmente escasa y de ahi creemos que procede la laguna fundamental de la visión de Keynes: nos parece que no percibe la auténtica dimensión de la crisis industrial del Reino Unido, que está ligada al predominio de un modelo cultural que no sitúa el hecho empresarial en el primer plano de atención económica y consideración social, en contraste con las pautas de valoración de los Estados Unidos.

El interés de Keynes se concentró en la gran empresa, en los mercados organizados, pero no en el magma que hace posible el surgimiento de nuevas iniciativas. En Keynes la atención se dirige más a la ordenación de lo existente que al proceso de renovación en el mundo empresarial que promueve el futuro. En la lucha que sostuvo Keynes con el Tesoro, el Banco de Inglaterra y la City, oponiéndose a las politicas deflacionistas ligadas a la restauración y mantenimiento del patrón oro en la década de los veinte, el economista de Cambridge tuvo razón al señalar la dificultad del ajuste de los costes internos a una paridad sobrevalorada, pero ni él ni sus oponentes pusieron el énfasis en lo que nos parece lo esencial de la cuestión: la falta de pulso de la vida empresarial inglesa y las razones de este hecho. Varias décadas antes, Marshall, un académico enclaustrado, habia detectado con mayor sensibilidad las razones profundas del declive industrial ingles.

\section{BIBLIOGRAFIA}

\section{Bibliografia de Keynes}

Los volúmenes de la Collected Writings citados en este articulo son los siguientes:

II. The Economic Consequences of the Peace (1913). Publicado en 1971.

IV. A tract on Monetary Reform (1923). Publicado en 1971.

V. A Treatise on Money. The Pure Theory of Money (1930). Publicado en 1971.

VI. A Treatise on Money The Applied Theory of Money (1930). Publicado en 1971.

VII. The General Theory (1936). Publicado en 1973. 
IX. Essays in Persuasion (1931). Publicado en 1972.

X. Essays in Biography (1933). Publicado en 1972.

XIX. Activities 1922-1929. The Return to Gold and Industrial Policy. PART I y II. Publicado en 1981.

XX. Activities 1929-1931. Rethinking Employment and Unemployment Policies. Publicado en 1981.

XXI. Activities 1931-1939. World Crises and Policies in Britain and America. Publicado en 1982.

XXIV. Activities 19944-1946. The Transition to Peace. Publicado en 1979.

XXVII. Activities 1940-1946. Shaping the Post-War. Employment and Commodities. Pu. blicado en 1980 .

XXVIII. Social, Political and Literary Writings. Publicado en 1982.

\section{Autorescitados}

Bettron, L. (1988): «La recepción de Keynes en España», en Rafael Rubio de Urquia y otros. La berencia de Keynes. Alianza Universidad. Madrid.

BLALC, M. (1983): «The Clasical Economista and the Factory Acts: A Re-Examination». Publicado inicialmente en Quarterly Journal of Economics (mayo, 1959) e incluido en M. Blaug: Economic History and the History of Economics. Wheatsheaf Book: Great Britain, 1986, de donde se toman las referencias.

Fuentes Quintana, E. (1983): «John Maynard Keynes en España». Papeles de Economia n." 17 , pp. 237.334 .

Gonct, R. A. (1982): «Alfred Marshall on Industrial Organization: From Principles of Economics to Industry and Trade», incluido en J. C. Wood (ed.). Alfred Marshall. Critical Assessments. Croom Helm. London, Vol. IV, de donde se toman las referencias.

Gordoon, D. (1992): «Keynes’s First Principles», en Mark Skousen (ed.). Dissent on Keynes. A Critical Appraisal of kevnesian Economics, Praeger Publishers. Nueva York.

Girechr, A. G. (1983): «J. M. Keynes' Concept of Economic Science», Southern Economic Journal, Vol. 15, enero, 1949, pp. 249-266, incluido en J. C. Woon (ed.), John Maynard Keynes, Critical Assessments. Croom Helm. London 1983, Vol. I, de donde se toman las referencias.

Harrod, R. F. (1958: La vida de Jobn Maynard Keynes. Primera edición en inglés, 1951. Primera edición en español: Fondo de Cultura Económica. México, 1958, de donde se toman las referencias.

Johnson, H. G. (1983): «Keynes' General Theory: Revolution or War of Independence», Canadian Journal of Economics, Vol. 9 (4), noviembre, 1976, pp. 580-594. Incluido en J. C. Woon (ed.), Jobn Maynard Keynes, Critical Assessments. Croom Helms. Londres, 1983, Vol. II, de donde se toman las referencias.

Jominson, H. G. 1977: «Cambridge as an Academic Environment in the Early 1930s: A Reconstruction from the late 1940s», en D. PAJinkin and J. C. LelTh; Keynes, Cambridge and the General Theory; The Macmillan Press LTD. First edition 1977. Reprinted Great Britain, 1979.

LiRERA. INDUSTRIAL INQUiRy (1928): Britain's Industrial Future. Ernest Benn Limited. Great Britain. 
Marshall, A. (1964): Principles of Economics: An introductory volumen. Primera edicion 1890. Reimpresión de la octava edición. Macmillan and Co. LTD, Great Britain, de donde se toman las referencias. Existe version española de 1948 de la octava edi. ción inglesa. Editorial Aguilar.

Marshall, A. (1920): Industry and Trade. Primera edicion 1919. Macmillan and Co. LTD, 1932. Reimpresión de la tercera edición de 1920.

O'Bkies, D. P. (1989): Los economistas clásicos. Primera edición en inglés de 1975. Alianza Universidad. Madrid, de donde tomamos las referencias.

Plo;), A. C. (1966): Memorials of Alfred Marshall. Primera edicion 1925. Augusta M. Kelly. Publishers. Nueva York.

Skinliskr, R. (1992): John Maynard Keynes. The Economist as Saviour 1920-1937. Macmillan London Ltd.

Sintrites, A. (1983): «Keynes Revisited». Quarterly Journal of Economics. Vol. 86. Augusta, 1972, pp. 463.75, incluido en J. C. Wood (ed.); Jobn Maynard Keynes. Critical Assessments. Croom Helm. London, Vol. I, de donde se toman las referencias.

Torrfro, A. (1993): “Robert Skidelsky, John Maynard Keynes. The Economist as Sa. viour 1920-1937m. Revista de Economia Aplicada n." 2 (Vol. 1), pp. 233-241.

Vflarde Furetes, J. (1988): «Keynes en España», en R. Rubio dF. Uroula y otros (ed.), La Herencia de Keynes, Alianza Editorial, Madrid.

WHITAKER, J. K. (1982): «Some Neglected Aspects of Aldred Marshall's Economic and Social Thought", History of Political Economy, Vol. 9, n." 1, Spring 1977, pp. 161 197. Incluido en J. C. Woon (Ed.). Alfred Marshall Critical Assesaments. Croom Helm. Londres. Vol. (I), de donde se toman las referencias.

WIt.NEK, M. K. (1985): English Culture and the Decline of the Industrial Spirit 1850-1980. Primera edición 1981. Penguin Brooks, England.

WRIGHT, D. (1983): The Future of Keynesian Economics. American Economic Revieu: Vol. 35 (3), junio, 1945, pp. 248-307, incluido en J. C. Woov (ed.): Jobn Maynard Keynes, Critical Assessmenis. Croom Helm. Londres, Vol. III, de donde se toman las referencias. 